\title{
Comparative Study between Adductor Canal Block and Femoral Nerve Block for Postoperative Analgesia in Knee Arthroscopy
}

\author{
MAI K. ABDALLAH, M.Sc.; MOHAMAD G. EL-MAWY, M.D.; AHMED A. ABD EL-HAFEZ, M.D. and \\ SOHAIR M. SOLIMAN, M.D.
}

The Department of Anesthesiology \& Surgical Intensive Care, Faculty of Medicine, Tanta University

\begin{abstract}
Background: Femoral Nerve Block (FNB) is one of the easiest peripheral nerve blocks. However, prolonged motor blockade is associated with a clinically important risk of fall. With the advent of ultrasonography, the adductor canal can be easily visualized at the mid-thigh level, allowing performance of Adductor Canal Block (ACB) with a high success rate.

Aim: To compare the safety and efficacy of ultrasound guided adductor canal block versus ultrasound guided femoral nerve block as post-operative analgesic in patients undergoing knee arthroscopy.

Patients and Methods: This study was carried out in Tanta University Hospitals from September 2015 till March 2016 on 105 adult patients of both sexes with ASA physical status I/II scheduled for knee arthroscopy. Patients divided into three equal groups (Group I) received basic analgesia in the form of paracetamol and diclofenac, (Group II) received ultrasound guided FNB and (Group III) received ultrasound guided ACB.

Results: There were no significant differences among the three studied groups according to demographic data. Comparison of the mean value of NPS score showed no significant difference between FNB and ACB, but there were significant increase in control group in comparison to both FNB and $\mathrm{ACB}$. The first time to introduce morphine and total morphine consumption showed no significant difference between FNB and ACB. There was significant decrease of BBS score in FNB till 6-8h postoperative in comparison with control group and $\mathrm{ACB}$.

Conclusion: Ultrasound guided adductor canal block is efficient as ultrasound guided femoral nerve block in control post-operative pain in patients undergoing knee arthroscopy. Also ACB result in early mobilization with no risk of fall that renders $\mathrm{ACB}$ preferred.
\end{abstract}

Key Words: Post-operative analgesia - Adductor canal block - Femoral nerve block - Knee arthroscopy.

Correspondence to: Dr. Mai K. Abdallah, The Department of Anesthesiology \& Surgical Intensive Care, Faculty of Medicine, Tanta University

\section{Introduction}

KNEE arthroscopy is a very common procedure and often is performed as day-case surgery [1]. It has been reported that a significant number of patients have moderate to severe pain 24 hours after ambulatory surgery in general and knee arthroscopy in particular, and pain affects the patient's activity level and satisfaction [2]. In an effort to provide an effective, safe and long lasting postarthroscopy analgesia, several studies using different drugs and regimes have been published during the last two decades $[3,4]$. Intra-articular administration of local anesthetics has been widely used but some studies have questioned their efficacy [5].

The Femoral Nerve Block (FNB) is one of the easiest peripheral nerve blocks to master because the landmarks are generally easy to identify and the nerve is usually found at a superficial depth. However, prolonged motor blockade from FNB is associated with a small but clinically important risk of fall $[6,7]$.

With the advent of ultrasonography, the adductor canal can be easily visualized at the mid-thigh level, allowing performance of Adductor Canal Block (ACB) with a high success rate [8.9] .

\section{Patients and Methods}

After obtaining the research ethics committee approval (approval code: (30342/06/15) an informed consent was taken from each patient, a prospective single blind randomized study was carried out in Tanta University Hospitals from September 2015 till March 2016 on 105 adult patients of either sex, American Society of Anesthesiologists (ASA) class I \& II scheduled for knee arthroscopy either therapeutic or diagnostic, 
excluding the patients who refused to share in the study, those with history of hypersensitivity to local anesthetics and those with coagulopathies.

We also planned to exclude patients who were complaining of local infection at the site of the block, preexisting neuropathy and/or femoral AV malformation on the operative limb.

The total participant number reached 105 patients, each one was randomly assigned to one of the three equal groups using opaque sealed envelope. This randomization was done by independent assistant that didn't share in the next steps of the study.

\section{Group I (control group): (No. 35):}

Patients received intraoperative analgesia an intravenous paracetamol $1 \mathrm{gm}$ which was repeated orally every $6 \mathrm{~h}$ postoperatively and diclofnac $75 \mathrm{mg}$ infusion intraoperative then was repeated orally $25 \mathrm{mg}$ every $6 \mathrm{~h}$ post-operatively.

Group II (group FNB): (No. 35):

Patients received Femoral Nerve Block (FNB) after induction of general anesthesia.

Group III (group ACB): (No. 35):

Patients received Adductor Canal Block (ACB) after induction of general anesthesia.

\section{Patient management:}

In the anesthesia clinic:

History taking include (age and sex), careful examination to exclude any neurological deficit in lower limb and laboratory investigation. Patient education about the use of $0-10$ numerical pain scale (NPS: With endpoints of 0: 'no pain' and 10: 'worst pain imaginable).

\section{Intraoperative:}

Basic monitoring [ECG, Non-Invasive Blood Pressure (NIBP), oxygen saturation (SPO 2) using pulse oxymetry] was performed; an intravenous (I.V) line was general anesthesia was induced using $1 \mathrm{~g} / \mathrm{kg}$ of fentanyl and $2.0 \mathrm{mg} / \mathrm{kg}$ of propofol. Tracheal intubation was facilitated by $0.15 \mathrm{mg} / \mathrm{kg}$ cisatracurium after mask ventilation for 5 minutes. Muscle relaxation was maintained with additional doses $0.03 \mathrm{mg} / \mathrm{kg}$. Anesthesia was maintained with isoflurane 1-2 MAC. Controlled mechanical ventilation to keep endtidal $\mathrm{CO} 2$ between 34-37.

Techniques of nerve block:

\section{Equipment:}

-22-gauge $100 \mathrm{~mm}$ length, short-beveled regional block needle.
- Skin antiseptic solution $(0.5 \%$ Chlorhexidine spray).

- Sterile gloves, towels and gel.

- For femoral nerve block 30mls of $0.25 \%$ Bupivacaine.

- For Adductor canal block $15 \mathrm{mls}$ of $0.25 \%$ Bupivacaine.

- Portable ultrasound machine (Toshiba Viano U.S.A), a 6-12 MHz linear type probe.

Technique of FNB:

- Position: Supine position.

- The skin around the femoral crease was disinfected.

- Transducer positioned to identify femoral artery and nerve.

Once femoral nerve identified, the needle inserted in-plane in a lateral-to-medial orientation and advanced toward the femoral nerve. When the needle tip adjacent to the nerve, inject $30 \mathrm{ml}$ Bupivacaine $0.25 \%$.

\section{Technique of ACB:}

- Position: Supine.

- Thigh abducted and externally rotated to allow access to the medial thigh.

- Skin over mid-thigh disinfected.

- The transducer placed anteromedially midway between inguinal crease and medial condyle to identify sartorius muscle.

- Probe positioned perpendicular to artery and using in-plane technique with needle directed from lateral to medial to deposit local anesthetic under sartorius and around the femoral artery. We injected $15 \mathrm{ml}$ Bupivacaine $0.25 \%$.

\section{Post-operative:}

After recovery, all patients were transported to PACU for 2 hours then to the ward where observation was completed for 12 hours. Any patient with NPS > 4 intravenous morphine was titrated every $5 \mathrm{~min}$ in $3 \mathrm{mg}$ increments $(2 \mathrm{mg}$ in patients weighing $<60 \mathrm{~kg}$ ), and pain was assessed every 5 min until pain relief, defined as a NPS score less than 4.

Clinical monitoring included respiratory rate measurements, oxygen saturation measured by pulse oximetry, arterial blood pressure, and heart rate. Morphine titration was stopped if the patient had a respiratory rate lower than 12 breaths $/ \mathrm{min}$, 
had an oxygen saturation measured by pulse oximetry lower than $95 \%$.

\section{Results}

Statistical presentation and analysis of the present study was conducted, using the mean, standard deviation and chi-square test by SPSS V.16.

The age in Group I range from (19-39) years with mean value $26.9 \pm 5.65$, in Group II range from (18-39) years with mean value $28.5 \pm 5.6$ and Group III range from (20-40) years with mean value $29 \pm 6.3$ with insignificant difference when compared to each other as shown in (Table 1).

According to the sex in Group I show 18 male (51.4\%) and 17 female ( $48.6 \%$ ), in Group II show 20 male $(57.1 \%)$ and 15 female (42.9\%) and Group
III show 16 male (45.7\%) and 19 female $(54.3 \%)$ with insignificant difference among the three studied groups as shown in (Table 1).

ASA classes in Group I showed 23 patients ASA I $(65.7 \%)$ and 12 patients ASA II (34.3\%), in Group II 24 patients ASA I (68.6\%) and 11 patients ASA II (31.4\%) and in Group III 20 patients ASA I (57.1\%) and 15 patients ASA II (42.9\%) with insignificant difference among the three studied groups as shown in (Table 1).

BMI in Group I range from (18-36) min with mean value $24.57 \pm 5.09$, in Group II range from (17-37) min with mean value $27.17 \pm 5.8$ and Group III range from (16-36) min with mean value $26.69 \pm 6.28$ which show insignificant difference when compared to each other as shown in (Table 1).

Table (1): Comparison among the three studied groups according to demographic data (age, sex, ASA and BMI).

\begin{tabular}{|c|c|c|c|c|c|}
\hline \multirow{2}{*}{ Items } & \multirow{2}{*}{$\begin{array}{l}\text { Group I } \\
(\mathrm{n}=35)\end{array}$} & \multirow{2}{*}{$\begin{array}{c}\text { Group II } \\
(\mathrm{n}=35)\end{array}$} & \multirow{2}{*}{$\underset{(\mathrm{n}=35)}{\text { Group III }}$} & \multicolumn{2}{|c|}{ Tests } \\
\hline & & & & $\mathrm{f} \& \chi^{2}$ & $p$-value \\
\hline \multicolumn{6}{|l|}{ Sex: } \\
\hline Male & $18(51.4 \%)$ & $20(57.1 \%)$ & $16(45.7 \%)$ & 0.915 & 0.633 \\
\hline Female & $17(48.6 \%)$ & $15(42.9 \%)$ & $19(54.3 \%)$ & & \\
\hline \multicolumn{6}{|l|}{ Age (years): } \\
\hline Range & $19-39$ & $18-39$ & $20-40$ & 1.209 & 0.303 \\
\hline Mean \pm SD & $26.91 \pm 5.65$ & $28.51 \pm 5.61$ & $29 \pm 6.32$ & & \\
\hline \multicolumn{6}{|l|}{$A S A:$} \\
\hline ASA I & $23(65.7 \%)$ & $24(68.6 \%)$ & $20(57.1 \%)$ & 1.072 & 0.585 \\
\hline ASA II & $12(34.3 \%)$ & $11(31.4 \%)$ & $15(42.9 \%)$ & & \\
\hline \multicolumn{6}{|l|}{$B M I\left(K g / m^{2}\right):$} \\
\hline Range & $18-36$ & $17-37$ & $16-36$ & 2.024 & 0.137 \\
\hline Mean \pm SD & $24.57 \pm 5.09$ & $27.17 \pm 5.81$ & $26.69 \pm 6.28$ & & \\
\hline
\end{tabular}

Comparison of the mean value of NPS among the three studied groups revealed that there was significant decrease in Group II \& III in comparison with Group I at $30 \mathrm{~min}, 1 \mathrm{hr}, 2 \mathrm{hr}, 3 \mathrm{hr}, 4 \mathrm{hr}, 5 \mathrm{hr}, 6 \mathrm{hr}$, $8 \mathrm{hr}, 10 \mathrm{hr}$ and $12 \mathrm{hr}$ post-operatively as shown in (Table 2).

Comparison of the mean value of BBS (Berg Balance score) among the three studied groups revealed that there was no significant difference at the base line (preblock) but there was significant decrease in Group II in comparison with Group I \& Group III at $30 \mathrm{~min}$ after full recovery, $2 \mathrm{hr}, 4 \mathrm{hr}$, $6 \mathrm{hr}$ and $8 \mathrm{hr}$ postoperatively as shown in (Table 3 ).

Comparison among the three studied groups according to onset of 1 st dose morphine revealed that there was significant increase in Group II \& III in comparison with Group I as shown in (Table 4).

The total dose of analgesic consumption (morphine in $(\mathrm{mg})$ ) showed significant increase in Group I in comparison with Group II \& Group III ( $p$ value $<0.001)$ with insignificant change between Group II \& Group III ( $p$-value 0.943 ) as shown in (Table 5).

Duration of motor block (BBS score $<40$ ) in Group I \& Group III was 0hr. While in Group II ranged between $2-8 \mathrm{hr}$ with mean value $(4.68 \pm 1.3)$ $\mathrm{hr}$. In comparison among the three groups there was significant increase in Group II in comparison with Group I \& III as shown in (Table 6). 
Table (2): Comparison among the three studied groups according to NPS.

\begin{tabular}{|c|c|c|c|c|c|c|c|c|c|c|}
\hline & \multicolumn{10}{|c|}{ NPS (post-operative) } \\
\hline & $30 \mathrm{~min}$ & $1 \mathrm{hr}$ & $2 \mathrm{hr}$ & $3 \mathrm{hr}$ & $4 \mathrm{hr}$ & $5 \mathrm{hr}$ & $6 \mathrm{hr}$ & $8 \mathrm{hr}$ & $10 \mathrm{hr}$ & $12 \mathrm{hr}$ \\
\hline \multicolumn{11}{|l|}{ GI: } \\
\hline Mean & 4.31 & 4.23 & 4.26 & 3.89 & 3.77 & 4.06 & 4.51 & 4.34 & 4.0 & 4.46 \\
\hline SD. & 1.02 & 0.81 & 0.82 & 0.90 & 1.09 & 0.80 & 0.61 & 1.08 & 0.84 & 0.78 \\
\hline \multicolumn{11}{|l|}{ GII: } \\
\hline Mean & 1.13 & 1.28 & 1.28 & 1.31 & 1.34 & 1.38 & 1.47 & 1.50 & 1.53 & 1.38 \\
\hline SD. & 0.98 & 0.99 & 1.08 & 1.06 & 1.04 & 1.04 & 1.14 & 1.08 & 1.08 & 1.10 \\
\hline \multicolumn{11}{|l|}{ GIII: } \\
\hline Mean & 1.27 & 1.45 & 1.52 & 1.55 & 1.45 & 1.45 & 1.64 & 1.52 & 1.61 & 1.64 \\
\hline SD. & 0.91 & 0.90 & 0.91 & 0.87 & 0.94 & 0.90 & 0.90 & 0.83 & 0.97 & 0.93 \\
\hline H. test & $65.950 *$ & $67.099 *$ & $66.513 *$ & $61.809 *$ & $56.820 *$ & $63.500 *$ & $68.375^{*}$ & $63.008 *$ & $58.485^{*}$ & $66.172 *$ \\
\hline$p$-value & $<0.001 *$ & $<0.001 *$ & $<0.001 *$ & $<0.001 *$ & $<0.001 *$ & $<0.001 *$ & $<0.001 *$ & $<0.001 *$ & $<0.001 *$ & $<0.001 *$ \\
\hline$p 1$ & $<0.001 *$ & $<0.001 *$ & $<0.001 *$ & $<0.001 *$ & $<0.001 *$ & $<0.001 *$ & $<0.001 *$ & $<0.001 *$ & $<0.001 *$ & $<0.001 *$ \\
\hline$p 2$ & $<0.001 *$ & $<0.001 *$ & $<0.001 *$ & $<0.001 *$ & $<0.001 *$ & $<0.001 *$ & $<0.001 *$ & $<0.001 *$ & $<0.001 *$ & $<0.001 *$ \\
\hline p3 & 0.492 & 0.409 & 0.241 & 0.224 & 0.757 & 0.804 & 0.463 & 1.000 & 0.571 & 0.273 \\
\hline
\end{tabular}

p1: $p$-value for comparing between group I \& group II. p2: $p$-value for comparing between group I \& group III.

Table (3): Comparison among the three studied groups according to BBS.

\begin{tabular}{|c|c|c|c|c|c|c|c|}
\hline & \multicolumn{7}{|c|}{ BBS } \\
\hline & Pre & $30 \mathrm{~m}$ & $2 \mathrm{hr}$ & $4 \mathrm{hr}$ & $6 \mathrm{hr}$ & $8 \mathrm{hr}$ & $12 \mathrm{hr}$ \\
\hline \multicolumn{8}{|l|}{ Control: } \\
\hline Mean & 56.0 & 56.0 & 56.0 & 56.0 & 56.0 & 56.0 & 56.0 \\
\hline SD. & 0.0 & 0.0 & 0.0 & 0.0 & 0.0 & 0.0 & 0.0 \\
\hline \multicolumn{8}{|l|}{$F N B:$} \\
\hline Mean & 56.0 & 25.53 & 34.94 & 43.09 & 51.25 & 55.06 & 56.0 \\
\hline SD. & 0.0 & 5.45 & 4.63 & 5.28 & 4.87 & 2.14 & 0.0 \\
\hline \multicolumn{8}{|l|}{$A C B$} \\
\hline Mean & 56.0 & 56.0 & 56.0 & 56.0 & 56.0 & 56.0 & 56.0 \\
\hline SD. & 0.0 & 0.0 & 0.0 & 0.0 & 0.0 & 0.0 & 0.0 \\
\hline$F$-test & - & $1064.969 *$ & $705.235^{*}$ & $203.766^{*}$ & $32.353^{*}$ & $6.538 *$ & - \\
\hline$p$-value & - & $<0.001 *$ & $<0.001 *$ & $<0.001 *$ & $<0.001 *$ & $0.002 *$ & - \\
\hline$p 1$ & - & $<0.001 *$ & $<0.001 *$ & $<0.001 *$ & $<0.001 *$ & $0.002 *$ & - \\
\hline$p 2$ & - & 1.000 & 1.000 & 1.000 & 1.000 & 1.000 & - \\
\hline$p 3$ & - & $<0.001 *$ & $<0.001 *$ & $<0.001 *$ & $<0.001 *$ & $0.002 *$ & - \\
\hline
\end{tabular}

Table (4): Time till need for first dose of morphine in hours.

\begin{tabular}{lccc}
\hline & Group I & Group II & Group III \\
\hline Min. & 0.0 & 1.0 & 2.0 \\
Max. & 0.0 & 12.0 & 12.0 \\
Mean & 0.0 & 11.22 & 11.09 \\
SD. & 0.0 & 2.28 & 2.57 \\
\hline$H$-test & & 85.455 & \\
$p$-value & & $<0.001^{*}$ & \\
$p 1$ & $<0.001^{*}$ & \\
$p 2$ & & $<0.001^{*}$ & \\
$p 3$ & & 0.983 & \\
\hline
\end{tabular}

$p 1: p$-value for comparing between group I \& group II.

$p 2: p$-value for comparing between group I \& group III.

p3: $p$-value for comparing between group II \& group III.

*: Statistically significant at $p \leq 0.05$.
Table (5): Comparison among the three studied groups according to total morphine consumption (in $\mathrm{mg}$ ).

\begin{tabular}{llll}
\hline & Group I & Group II & Group III \\
\hline Min. & 6 & 0 & 0 \\
Max. & 25 & 20 & 20 \\
Mean & 14.11 & 1.37 & 2.29 \\
SD. & 4.63 & 3.87 & 4.78 \\
\hline$F$-test & & 57.947 & \\
$p$ & & $<0.001$ & \\
$p 1$ & $<0.001$ & \\
$p 2$ & $<0.001$ & \\
$p 3$ & & 0.943 & \\
\hline
\end{tabular}

p1: $p$-value for comparing between group I \& group II $p 2: p$-value for comparing between group I \& group III p3: $p$-value for comparing between group II \& group III $p_{*}^{3}:$ Statistically significant at $p \leq 0.05$ 
Table (6): Comparison among the three studied groups according to duration of motor block (in hours).

\begin{tabular}{lccc}
\hline & Group I & Group II & Group III \\
\hline Min. & 0.0 & 2.0 & 0.0 \\
Max. & 0.0 & 8.0 & 0.0 \\
Mean & 0.0 & 4.68 & 0.0 \\
SD. & 0.0 & 1.3 & 0.0 \\
\hline$F$-test & & 438.56 & \\
$p$ 1 & & $<0.001^{*}$ & \\
$p 2$ & & 1.00 & \\
$p 3$ & & $<0.001^{*}$ & \\
\hline
\end{tabular}

1: $p$-value for comparing between group I \& group II. p2: $p$-value for comparing between group I \& group III. p3: $p$-value for comparing between group II \& group III. $*$ : Statistically significant at $p \leq 0.05$

\section{Discussion}

Peripheral nerve blocks are associated with less pain and lower odds of unplanned hospital admission compared to systemic analgesia [10]. The decision regarding continuous versus singleinjection depends on the expected surgical trauma and patient factors [11]

Benefits of ACB may include shorter hospital stays, earlier and more efficient rehabilitation, and pain control. Additionally, patients will retain the ability to report pain in neighboring distributions that can be involved when attempting to block the femoral nerve at the inguinal crease. This technique also embraces the emerging regional philosophy of selectivity or blocking only the area involved in the surgery [12].

The most important advantage of ultrasound for peripheral nerve block PNB is the ability to confirm local anesthetic spread around the target nerve. This is the difference from conventional blind techniques, which can fail because local anesthetic does not uniformly surround the target nerve [13]

In our study, there was no significant difference among the three studied groups as regard to demographic data (age, sex, ASA \& BMI).

Comparison of the mean value of NPS score among the studied groups revealed that there was no significant difference between FNB and ACB ( $p$-value 0.54$)$, but there were significant increase in control group in comparison to both FNB and ACB ( $p$-value <0.001).

The first time to introduce morphine and total morphine consumption showed no significant difference between FNB and ACB ( $p$-value 0.983,
0.0943) respectively, but there were significant increase in control group in comparison to both FNB and ACB ( $p$-value <0.001).

While comparison of the mean value of BBS score among the studied groups revealed that there was no significant difference between control group and $\mathrm{ACB}$, there was significant decrease of BBS score in FNB till 6-8h post-operatively in comparison with control group and ACB ( $p$-value $<0.001$, $<0.001)$ respectively, indicating high risk of falling.

In agreement with our results, Hanson et al., [14] stated that all patients received ACB were able to stand in the post Anesthesia Care Unit and no study participant subjectively mentioned leg weakness or reported falls within postoperative 24 hours. However, they didn't objectively measure the quadriceps muscle strength.

Kwofie et al., [15] demonstrated that Quadriceps strength and balance scores were similar to baseline following ACB. Following FNB, there was a significant reduction in quadriceps strength.

David et al., [16] estimated that the FNB would result in at least $50 \%$ decrease in motor strength in comparison with the saphenous nerve block.

Jaeger et al., [17] reported that FNB reduced $49 \%$ of quadriceps strength from baseline but ACB caused only $8 \%$ reduction in healthy young subjects.

In controversy to our results, Espelund et al., [18] concluded that there were no significant analgesic effect of the ACB after minor arthroscopic knee surgery with a basic analgesic regimen.

El-Ahl, [19] found that the VAS pain score and opioid consumption was significantly higher in patients received ACB than FNB.

\section{Conclusion and Recommendation:}

Ultrasound guided ACB should be considered as a safe efficient alternative to ultrasound guided FNB for post-operative pain in cases of knee arthroscopy. Also ACB results in early mobilization with no risk of fall and that renders ACB preferred.

\section{References}

1- WEALE A.E., ACKROYD C.E., MANI G.V. and WINSON I.G.: Day-case or short-stay admission for arthroscopic knee surgery: A randomised controlled trial. Ann. R. Coll. Surg. Engl., 80 (2): 146-9, 1998.

2- PAVLIN D.J., CHEN C., PENALOZA D.A. and BUCKLEY F.P.: A survey of pain and other symptoms that affect the recovery process after discharge from an ambulatory surgery unit. J. Clin. Anesth., 16 (3): 200-6, 2004. 
3- RUWE P.A., KLEIN I. and SHIELDS C.L.: The effect of intraarticular injection of morphine and bupivacaine on postarthroscopic pain control. Am. J. Sports. Med., 23 (1): 59-64, 1995.

4- KAEDING C.C., HILL J.A., KATZ J. and BENSON L.: Bupivacaine use after knee arthroscopy: Pharmacokinetics and pain control study. Arthroscopy, 6 (1): 33-9, 1990.

5- MOINICHE S., MIKKELSEN S., WETTERSLEV J. and DAHL J.B.: A systematic review of intra-articular local anesthesia for post-operative pain relief after arthroscopic knee surgery. Reg. Anesth. Pain. Med., 24 (5): 430-7, 1999.

6- ATKINSON H.D., HAMID I., GUPTE C.M., RUSSELL R.C. and HANDY J.M.: Post-operative fall after the use of the 3-in-1 femoral nerve block for knee surgery: A report of four cases. J. Orthop. Surg. (Hong Kong), 16: 381-4, 2008.

7- LI D., TAN Z., KANG P., SHEN B. and PEI F.: Effects of multi-site infiltration analgesia on pain management and early rehabilitation compared with femoral nerve or adductor canal block for patients undergoing total knee arthroplasty: A prospective randomized controlled trial. International Orthopaedics, 41 (1): 75-83, 2017.

8- JAEGER P., GREVSTAD U., HENNINGSEN M.H., GOTTSCHAU B., MATHIESEN O. and DAHL J.B.: Effect of adductor-canal-blockade on established, severe post-operative pain after total knee arthroplasty: A randomised study. Acta Anaesthesiol Scand., 56: 1013-9, 2012.

9- MANICKAM B., PERLAS A., DUGGAN E., BRULL R., CHAN V.W. and RAMLOGAN R.: Feasibility and efficacy of ultrasound-guided block of the saphenous nerve in the adductor canal. Reg. Anesth. Pain. Med., 34: 578-80, 2009.

10- WILLIAMS B.A., KENTOR M.L., VOGT M.T., WILLIAMS J.P., CHELLY J.E., VALALIK S. and HARNER C.D.: Femoral-sciatic nerve blocks for complex outpatient knee surgery are associated with less postoperative pain before same-day discharge: A review of 1,200 consecutive cases from the period 1996-1999. Anesthesiology, 98 1206-13, 2003.
11- WILLIAMS B.A., KENTOR M.L., VOGT M.T., et al.: Reduction of verbal pain scores after anterior cruciate ligament reconstruction with 2-day continuous femoral nerve block: A randomized clinical trial. Anesthesiology, 104: 315-27, 2006.

12- NEAL J.M., BARRINGTON M.J., BRULL R., HADZIC A., HEBL J.R., HORLOCKER T.T., and WATSON J.C.: The second ASRA practice advisory on neurologic complications associated with regional anesthesia and pain medicine: Executive summary 2015. Regional. Anesthesia And Pain Medicine, 40 (5): 401-30, 2015.

13- KELLY L., FRITSCH B., LANSDOWN A., and KAM P.: The subsartorial approach to continuous adductor canal block: Safer. Reg. Anesth. Pain. Med., 42: 413-4, 2017.

14- HANSON N., DERBY R. and AUYONG D.B.: Ultrasound-guided adductor canal block for arthroscopic medial meniscectomy: A randomized, double-blind trial. Can. J. Anaesth., 60 (9): 874-80, 2013.

15- KWOFIE M.K. and SHASTRI UMA D.: The effects of ultrasound-guided adductor canal block versus femoral nerve block on quadriceps strength and fall risk: A blinded, randomized trial of volunteers. Reg. Anesth. Pain. Med., 38: 321-5, 2013.

16- DAVID H. KIM., ENRIQUE A. GOYTIZOLO and RICHARD L. KAH: Adductor Canal Block versus Femoral Nerve Block for Total Knee Arthroplasty: A Prospective, Randomized, Controlled Trial Anesthesiology, 120: 54050, 2014.

17- PIAJÆGER, ZBIGNIEW J.K. NIELSEN and D.M.S.C.I.: Adductor canal block versus femoral nerve block and quadriceps strength: A randomized, double-blind, placebocontrolled, crossover study in healthy volunteers. Anesthesiology, 118: 409-15, 2013.

18- ESPELUND M., FOMSGAARD J.S., HARASZUK J., DAHL J.B. and MATHIESEN O.: The efficacy of adductor canal blockade after minor arthroscopic knee surgery-a randomized controlled trial. Acta. Anaesthesiol. Scand., 58 (3): 273-80, 2015.

19- EL-AHL M.S.: Femoral nerve block versus adductor canal block for postoperative pain control after anterior cruciate ligament reconstruction: A randomized controlled double blind study. Saudi. J. Anaesth., 9 (3): 279-82, 2015. 


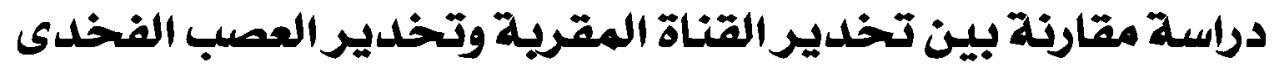

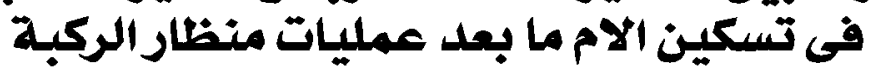

عادة ما تسبب جراحات منظار الركبة في آلام شديدة فيما بعد العملية لمدة ع باعة، لذا يعد تخدير الآعصاب الطرفية فعالة وآمنة وطويلة المدى كمسكن لتلك العمليات. وقد آدى إستخدام الموجات فوق الصوتية إلى إرتفاع نسبة نجاح تخدير الآعصاب الطرفية. وكان من شان تخدير الآعصاب الطرفية آن توفر المريض القدرة المبكرة على الصركة، بالإضافة إلى تسكين آلام ما بعد الجراحة. ولما كان لتخدير العصب الفخذى تاثير فعال على قدرة المريض على الحركة فيما بعد العملية فقد إتجهت الآبحاث مؤخرا إلى إستخدام

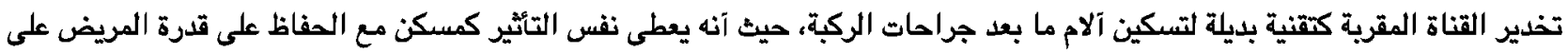
الحركة فيما بعد الجراحة.

وكان الهدف من البحث: دراسة مقارنة بين تخدير العصب الفخذى وتخدير القناة المقربة بإستخدام الموجات فوق الصوتية للتحكم فى آلام ما بعد عمليات منظار الركبة.

حيث تضمن البحث ه ـا من المرضى البالفين المصنفين من الفئة الآلمى آو الثانية حسب تصنيف الجمعية الآمريكية للتخدير والذين خضعوا

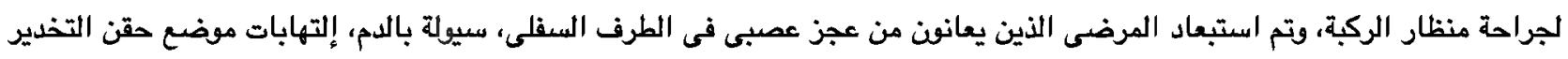

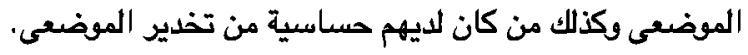

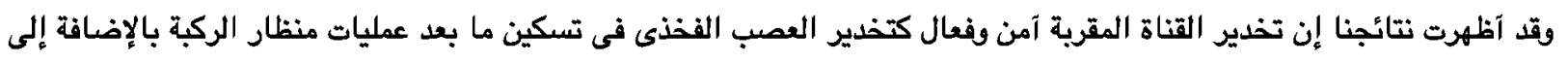
إعطاء المريض القدرة على الحركة المبكرة فيما بعد العملية. 